DOI: 10.2478 /ausp-2020-0027

\title{
The Treatment of Final Coda Consonants in the Acquisition of Romanian Phonology
}

\author{
Elena BUJA \\ Department of Theoretical and Applied Linguistics \\ Transilvania University of Braşov \\ elena_buja@yahoo.com
}

\begin{abstract}
Final consonant deletion has been attested in the acquisition of English (Johnson-Reimers 2010), Chinese (Hua 2002), Dutch (Fikkert 1994), Hebrew (Adi-Bensaid 2015), Spanish (Goldstein-Citron 2001), and Indonesian (Ulaimah et al. 2016). Previous studies on the acquisition of Romanian phonology (Buja 2015a, b) indicated an extremely low incidence of this phenomenon among the Romanian-speaking children. A possible explanation for it could be the inconsistency in collecting the data (child diaries and longitudinal corpora). By means of an experimental study, i.e. a picture-naming task, this paper aims to prove whether Romanian children do drop final coda consonants. The words describing the pictures presented to the children have a $\mathrm{C}_{1(-2)} \mathrm{VC}_{1}$ structure (e.g. drum 'road, way', cap 'head', nas 'nose'). The subjects in this small-scale research study were nine monolingual Romanian children aged between 2 and 4 years, who were recorded by their parents. Their spontaneous or imitated productions of the target words were transcribed by using IPA.

The results of the analysis confirm the predictions made in my previous study (Buja 2015b) - namely that final consonant deletion, a very frequent phonological process in the acquisition of various other languages, is not characteristic of the acquisition of Romanian phonology.
\end{abstract}

Keywords: phonological acquisition, phonological processes, final coda deletion, Romanian language

\section{Introduction}

In order to be able to produce their first words and, later on, their first sentences, children need to be in command of the sounds in their mother tongues. But before they acquire the adult phonology, children go through a number of stages, in which the production of particular sounds is affected by various errors that may turn into patterns. By comparing these speech sound patterns in a number of languages, scholars realized that they are common to children exposed to different ambient 
languages and that they occur quite regularly to be considered as natural processes (Stampe 1973) or phonological processes (Ingram 1974). According to Ingram, these processes affect both the segmental level (assimilation and substitution) and the suprasegmental level of language (consonant cluster reduction, deletion of initial/ final consonants). "Phonological processes perpetuate tendencies present in the babbling that precedes the onset of meaningful speech, such as the tendency to use stops, nasals, and glides rather than other consonants, and the tendency to use CV syllables in preference to more complex syllables" (Bosma Smit 1993: 533).

Previous studies on the acquisition of Romanian phonology (Buja 2015a, b) have shown that Romanian-speaking children pattern in many respects with their peers acquiring English and Spanish in terms of the segmental processes, but that they very seldom delete the final consonants in words. A possible explanation for this finding could be the fact that the data employed in those studies were not very consistent in the sense that some data were excerpts from child diaries kept by parents (friends and colleagues of mine, who agreed to share information about the linguistic development of their children with me), while some others were taken from four longitudinal corpora which contained naturally occurring exchanges between the toddlers and their adult caretakers. In these exchanges/pieces of discourse, lexical items do not appear in their dictionary form but undergo various changes imposed by the grammar of Romanian (use of the definite article, which is enclitic in this language, use of suffixes indicating case, number, and gender of the nouns or adjectives, inflections indicating person, number, and tense of verbs, etc.). To counter this possible bias, the current study focuses only on the acquisition of final consonants in simple, monosyllabic words, which Romanianacquiring children aged between 2 and 4 years have to produce in a picture-naming task. I assume that having no linguistic context provided, my young subjects would produce the dictionary form of the words, enabling me to identify if they delete or preserve the final consonants in the target lexical items and if they indeed preserve the final consonantal sounds, whether these are uttered appropriately or are affected by individual simplification strategies.

The paper is structured as follows: the next section offers a brief overview of the studies on this phenomenon in other languages. Section 3 presents the research methodology (selection of the subjects, devising the picture-naming task, data collection, and transcription) as well as the research questions; the findings of the analysis are discussed in Section 4, while the last part of the paper presents some tentative conclusions. 


\section{Literature review}

Studies on the acquisition of phonology have initially focused on English-speaking children (Moskowitz 1970, Smith 1973, Olmested 1971). Recently, a surge of interest in other languages has been noticed, scholars taking a look at the way in which children of other language backgrounds (Spanish - Goldstein 1995, Barlow 2005, Lléo 2009; Arabic - Owaida 2015; Tamil - Perumal 2019; Indonesian - UlaimahWijayadi-Hamsia 2016; Malay - Phoon-Abdullah-Lee-Murugaiah 2014; Hindi Kaur-Anand-Subbarao 2017, to mention just a few) acquire the phonology of their mother tongue. Many of these studies aimed at establishing the time of emergence of certain sounds and of mastery of the whole inventory by young children (Templin 1957), others focused on the order in which sounds were acquired (Olmsted 1971, Prather et al. 1975, Vihman et al. 1986), while many others considered the error patterns encountered in children's production of sounds (Grunwell 1981, Bosma Smit 1993). One frequent error reported for children acquiring various languages is final coda deletion.

A study conducted on a group of 50 English-speaking children aged between 3 and 5 years by Haelsig and Madison (1986) showed that final consonant deletion is more frequent among the youngest children in the study and decreases by 50 percent in children aged 4 years. A somewhat different finding concerning the deletion of final consonants emerged from the research carried out by Stoel-Gammon and Dunn (1985), who reviewed a number of studies on phonological processes affecting the speech production of English-speaking children. Thus, the two scholars state that the deletion of final consonants comes to an end by age 3. Bosma Smit (1993) studied the consonant errors produced by 1,049 English-acquiring children with ages between 2 and 9 years as one-word responses in a picture-naming task. The results of the investigation showed that the younger subjects in the study frequently deleted wordfinal plosives and fricatives, this deletion applying $5-15 \%$ of the time. Apart from considering the consonant production of an extremely large number of children, this study has got additional merits in that the errors produced by children are typical of certain consonants and of a certain word position (initial, mid, or final). Moreover, Bosma Smit also classified the error types encountered in the data into typical and atypical depending on the frequency of their occurrence (atypical errors are the ones with a frequency between 1 and $4 \%$ in the total number of productions).

Kaur, Anand, and Subbarao (2017) investigated the phonological processes that 30 Hindi-speaking children made recourse to. The subjects' age ranged between 3 and 4 years, and they were divided into two groups depending on whether they came from an urban or a rural area in New Delhi. Among the 25 identified phonological processes, the authors mention final consonant deletion.

A number of studies have been carried out on the acquisition of Tamil, the results indicating contradictory findings. Final consonant deletion has been reported by 
Venkatesh et al. (2010) for both monolingual Tamil-speaking children and for TamilTelugu bilinguals aged between 4 and 6;6 years, this process being less frequent in the monolingual subjects and eliminated by the age of 5. Other studies (Perumal et al. 2017) do not report on the occurrence of this phonological process, a reason being the fact that in the spoken form of Tamil "words always end with a neutral vowel, and never with a consonant” (Perumal et al. 2017: 318).

The process of globalization has brought along large waves of migrants and international marriages that resulted quite often in bilingual children. Thus, scholars in the field of child language acquisition took an interest in the phonological acquisition in bilingual children, trying to see if final coda deletion does occur and the extent to which this phonological process differs from that encountered in monolingual speakers. A number of studies compared the phonological skills of English-Spanish bilinguals to those of monolingual English speakers and monolingual Spanish speakers (Gildersleeve-Davis-Stubbe 1996, Goldstein-Washington 2001). In investigating the occurrence of phonological processes in 12 typically developing Spanish-English bilingual children aged 4, Goldstein and Washington (2001) identified that among the syllable structure processes the ones that occurred both in English and Spanish were final consonant deletion, cluster reduction, and deletion of unstressed syllables, final consonant deletion being the most common process in English, whereas in Spanish cluster reduction was predominant. Others compared the phonological system of Spanish-German bilinguals to those of monolingual Spanish and German speakers (Lléo-Kuchenbrandt-Kehoe-Trujillo 2003) or simply presented the phonological development of an Arabic-Englishacquiring bilingual child (Daana 2017). The latter study focused on the one-word production period (7 to 20 months) of the subject (the researcher's own son) and revealed that the words produced by the child in an early stage had exclusively a CV syllable structure though in many cases the target word had a CVC form ([ba] < $/ \mathrm{b} \Lambda \mathrm{s} /$, [kæ] </kæt/ (English) and [na:] </na:m/ ('slept' $-3^{\text {rd }}$ pers. sg.) or [ko:] $</$ ko:l/ 'eat' (Arabic). A little later (though the author does not mention the exact age), the child starts producing closed monosyllabic words - more such words in English than in Arabic -, whose singleton codas were pronounced appropriately in most of the cases in both languages ([fav] </faiv/, [pu:n] </spu:n/, [hed] $</$ hed/ (English) and [na:m] </nam/ 'sleep', [ba:b] </ba:b/ 'door', [bat] </kta:b/ 'book' (Arabic).

In investigating the phonological development of an English-Romanian bilingual child, Avram (2016) focused mainly on the processes that affect the consonants in onset position in both languages. Even if the article did not consider the phenomenon of final coda deletion, the examples provided by the Romanian scholar indicated that in an early stage (age 1;3) the subject deleted the final consonants in the English words ([pa:] for 'park'), but a month later $(1 ; 4)$ he started producing the consonants in coda position appropriately, except for the lateral liquid: ([hın] 'sun', [pam] 'come', [ $\left.\mathrm{t}^{\mathrm{h}} \mathrm{\jmath p}\right]$ 'stop', [jed] 'red', or [kwi:n] 'clean'). 
A general picture that emerges from the literature review is that children acquiring different languages show a tendency to delete final coda consonants, but there are differences related to the age when this process seems to come to an end. This and the results of a previous study of mine motivated me to find out how Romanianspeaking children handle final coda consonants, in an attempt to contribute with Romanian data to the growing database on the phonological development of children with various language backgrounds.

\section{Research methodology}

\subsection{Material development}

In order to collect the data necessary for my study, a first step was to create a list of monosyllabic words with consonant codas, whose meanings should match the level of understanding of the youngest subjects in the study. To this aim, the website http:// speech-therapy.ca/index.php/ro/free-stuff-ro-menu/carte-1 proved extremely useful in that it provided words ending both in singletons and consonant clusters that can occur in Romanian. The list I have compiled comprises 38 words, whose codas cover 15 consonants. The number of lexical items containing a certain final consonant differed for two reasons: on the one hand, some consonants are very rare in coda position in Romanian. This is the case for $/ \mathrm{j} /$, which occurs in words of French origin (bej 'beige', ruj 'lipstick'), or /h/ (duh 'Holy Ghost', şah 'chess'). On the other hand, there are other consonants, which are licensed in coda position in Romanian, only that they do not appear in words that the majority of the toddlers are familiar with.

The second step was to search the Internet for coloured pictures corresponding to the words in the list. The photos were inserted in a table (four pictures on an A4 sheet), each with the word/words ${ }^{1}$ below them as in all cases the data were recorded by the children's caretakers/parents, and they needed to have clues regarding the words they were to elicit from the children. The words were arranged in the table in such a way that no two lexical items ending in the same consonant should appear close to each other in order to ensure a high level of accuracy in the production of the final consonants. The pictures were presented to the children who were expected to produce the target words spontaneously, without any adult model. Nevertheless, in some situations, when the children were not familiar with the word, they were helped by their parents (and sometimes by their older siblings) to name them. The caretaker would utter a short sentence containing the target word, after which s/he would ask the child what the image represented or simply to repeat the word, an illustration of the elicitation task being given below.

1 In some situations, the pictures assessed two or more consonants (e.g. moş 'old man', sac 'sack' or tren 'train', fum 'smoke', coş 'chimney/smokestack'). 
(1) Mo: Ce-i ăsta? 'What's this?'

Mara: $\mathrm{Nu}$ (ş)tiu. 'I don’t know.'

Mo: Nu ştii ce e ăsta? Nu prea te lasă mama să umbli cu aşa ceva. Este un ac. 'You don't know what this is? Mommy does not let you handle something like this. It is a needle.'

Mara: Este un ac? 'It's a needle?'

Mo: Da, cu care coasem. Coasem cu acul. 'Yes, we sew with it. We sew with the needle.'

\subsection{Participants}

The major problem I was confronted with was that of finding the subjects for the study. I have contacted the headmistress of one kindergarten in Braşov, whom I knew personally and to whom I explained the aim of my study and the reason why I needed access to the children in the institution she was running, but, much to my disappointment, she was not helpful at all, invoking the parents' lack of consent in having their offspring used as subjects in a research. A second option was suggested to me by a former student of mine, the mother of a trilingual 2-year old son, namely a forum for mothers of young children - Mămici de pitici. As this is a closed group, she offered to place a message on the forum, explaining what I was looking for, but to no avail: not even one mother offered to help me. My last resort was to appeal to my former students and to relatives who I knew had young children. Thus, I contacted each and every one of them via e-mail, phone, or Facebook, explaining in great detail what I was after. From among 20 such persons who initially showed willingness to contribute with data from their children or grandchildren, only 8 proved to finally accomplish the picture-naming task with the toddlers, one of the adults recording both her own child and also the child of a friend, the total number of subjects in the study being 9. I take this opportunity to express my deepest gratitude for their help. ${ }^{2}$

Though my initial intention was to collect data from children under 2 years of age, I realized that at the age of 1;6, children have a restricted vocabulary and may not have the patience or willingness to complete the picture-naming task. Thus, I opted for 2 years as the lowest and 4 years as the highest limit of the age range for my subjects, the latter being the age when children of different linguistic backgrounds are reported to be over consonant error patterns.

The table below contains information about the children in the study. For ethical reasons, only the children's given names are mentioned. All children come from a similar socio-economic background (middle-class families), their parents holding a BA or a master's degree in various fields (humanities and economic sciences).

2 I am greatly indebted to the following persons, who jumped in to help me with data from their children: Paula Leonte, Anca Buja, Aurelia Lalău, Cătălina Urdea, Simona Luca, Delia Macaveiu, and Marius Neculai. 
Table 1. Data concerning the subjects in the study

\begin{tabular}{llccc}
\hline No & Child's name & Child's age & Child's gender & Length of the recording \\
\hline 1 & Mara & $2 ; 1$ & $\mathrm{~F}$ & $21 \mathrm{~min} 54 \mathrm{sec}$ \\
\hline 2 & Ciprian & $3 ; 0$ & $\mathrm{M}$ & $5 \mathrm{~min} 46 \mathrm{sec}$ \\
\hline 3 & Ioana & $3 ; 3$ & $\mathrm{~F}$ & $4 \mathrm{~min} 08 \mathrm{sec}$ \\
\hline 4 & Maya & $3 ; 5$ & $\mathrm{~F}$ & $7 \mathrm{~min} 41 \mathrm{sec}$ \\
\hline 5 & Ana & $3 ; 10$ & $\mathrm{~F}$ & $4 \mathrm{~min} 58 \mathrm{sec}$ \\
\hline 6 & Vlad & $3 ; 10$ & $\mathrm{M}$ & $4 \mathrm{~min} 34 \mathrm{sec}$ \\
\hline 7 & David & $3 ; 11$ & $\mathrm{M}$ & $7 \mathrm{~min} 36 \mathrm{sec}$ \\
\hline 8 & Mihai & $3 ; 11$ & $\mathrm{M}$ & $11 \mathrm{~min} 56 \mathrm{sec}$ \\
\hline 9 & Elena & $4 ; 0$ & $\mathrm{~F}$ & $9 \mathrm{~min} 55 \mathrm{sec}$ \\
\hline
\end{tabular}

\subsection{Data collection: Recording and transcription}

The speech samples were audio or video recorded in a single session for each child, the time span varying between 4:34 and 21:54 minutes. I received the recordings via WhatsApp and transcribed them phonetically. In order to increase the reliability of transcriptions, they were double-checked. As sometimes the subjects were not able to respond appropriately, they were provided with prompts and cues or were asked to repeat the word. Thus, an issue that needed to be clarified was what to consider a target coda. If the child pronounced spontaneously and correctly the final consonants, s/he would be assigned a score of 1 ; if the final singletons were omitted altogether, the score was 0 , whereas if the coda was produced, but suffered 'repair strategies' (Jordão-Frota 2010: 2) or if the child produced the final consonants by repeating/imitating the adult model, a score of 0.5 was given. The first and the last categories were considered 'produced codas'.

\subsection{Data analysis}

Each of the final consonants was analysed using as many items as possible (see Table 2 below). The target words in the picture-naming task contained 15 coda singleton consonants, of which 11 obstruents (5 voiced: /b/, /d/, /g/, /v/, and /z/ and 6 voiceless: $/ \mathrm{p} /, / \mathrm{t} /, / \mathrm{k} /, / \mathrm{s} /, / \mathrm{J} /$, and $/ \mathrm{ks} /$ ) and 4 sonorants ( 2 nasals: $/ \mathrm{m} / \mathrm{and} / \mathrm{n} /$ and 2 liquids:/r/ and /l/). 
Table 2. Singleton codas: types and tokens

\begin{tabular}{|c|c|c|}
\hline Classes of consonants & $\begin{array}{c}\text { Consonants } \\
\text { (types) }\end{array}$ & No. if items tested (tokens) \\
\hline \multirow{11}{*}{$\begin{array}{l}\frac{0}{0} \\
\frac{0}{0} \\
\frac{0}{0}\end{array}$} & $\mathrm{p}$ & 3 \\
\hline & $\mathrm{b}$ & 1 \\
\hline & $\mathrm{t}$ & 3 \\
\hline & $\mathrm{d}$ & 1 \\
\hline & $\mathrm{k}$ & 7 \\
\hline & $\mathrm{g}$ & 1 \\
\hline & $\mathrm{V}$ & 1 \\
\hline & $\mathrm{s}$ & 4 \\
\hline & $\mathrm{z}$ & 1 \\
\hline & ş & 3 \\
\hline & $\mathrm{x} / \mathrm{ks} /$ & 1 \\
\hline \multirow{4}{*}{ 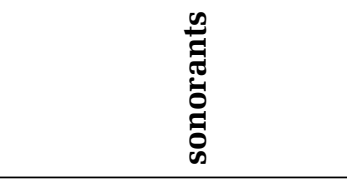 } & $\mathrm{m}$ & 3 \\
\hline & $\mathrm{n}$ & 4 \\
\hline & $\mathrm{r}$ & 2 \\
\hline & l & 3 \\
\hline TOTAL & 15 & 38 \\
\hline
\end{tabular}

\subsection{Research questions}

Due to the fact that in comparison with the onset the coda position is weak, and thus not so prominent for the children to perceive and produce it properly, I assume that the subjects in my study will show a tendency of deleting the final consonants, just like their peers speaking other languages (English - Vihman 1996, Fikkert 1994; Spanish - Borràs-Comes-Prieto 2013). Derived from this hypothesis, the following research questions will be addressed:

a) Do Romanian children delete final singleton codas and, if so, what type of final consonants are predominantly deleted by the subjects in the study?

b) What repair strategies do Romanian-speaking children use for the coda consonants?

c) To what extent do Romanian-speaking children pattern in the development of word codas with children acquiring other languages as their mother tongues?

d) What are the factors that might explain the possible differences between the Romanian children and those acquiring other L1s? 


\section{Findings and discussion}

The children in the present study showed both similarities and differences with respect to the production of the word-final consonants. The similarity consists in the fact that when they uttered the words corresponding to the pictures in the picturenaming task, either spontaneously or by repeating/imitating the adult model, all of them produced the final consonants (none of them deleted them).

Table 3. Overall picture of coda production by Romanian children

\begin{tabular}{ccc}
\hline Total of target words & Total of children & Total of words expected \\
\hline 38 & 9 & 342 \\
\hline $\begin{array}{c}\text { Total of words produced } \\
\text { spontaneously }\end{array}$ & $\begin{array}{c}\text { Total of words repeating } \\
\text { adult targets }\end{array}$ & $\begin{array}{c}\text { Total of words that were } \\
\text { not produced at all }\end{array}$ \\
\hline $236(69 \%)$ & $85(24.8 \%)$ & $21(6.1 \%)$ \\
\hline
\end{tabular}

As the data in Table 3 show, apart from those instances in which the children failed to produce the elicited word either spontaneously or by repeating the adult model ( $6.1 \%$ of the total final coda productions in the corpus), final coda consonants are present in the speech of the Romanian-speaking children in the study, a finding which is in stark contradiction with the results obtained by scholars investigating other languages. There are a number of reasons that may explain why the Romanian children, unlike the subjects in studies on the acquisition of word-final codas in other languages, did not delete the consonants.

a) One possible explanation would be that the subjects in this study are in a later phase of phonological development, when codas consisting of singletons are already in place. As shown in the study carried out on normally developing Hebrew-speaking children by Shaked (1990), final consonant deletion was encountered in children aged between 1;7 and 2;2 years, whereas the youngest subject in my study was already 2;1 years of age. Thus, a possible limitation of the current study resides in the fact that it may have missed an earlier period when Romanian children dropped the final codas.

b) Since all the words in the picture-naming task were monosyllabic content words ( 35 nouns and 3 adjectives), which in conversation carry stress, I assume that this could be another reason why Romanian-speaking children preserve the final coda. This supports the findings of other scholars investigating the acquisition of languages such as Spanish (Lléo 2003), Portuguese (Freitas et al. 2001), or English (Zamuner-Gerken 1998), who identified that children aged 2 tend to preserve final codas in the case of stressed syllables and delete them in unstressed syllables due to the fact that the former are more prominent acoustically in that they have a higher pitch, a longer duration, and a higher amplitude than the latter (Ladefoged 2011). Thus, children perceive such syllables much better and also produced them more appropriately than the unstressed ones. 
c) A third factor that explains final coda preservation by Romanian children could be the adult input: parents often address young toddlers by using diminutives, and thus the latter tend to produce these forms of the nouns. Five of my subjects (Mara - 2;1, Ciprian - 3;0, Mihai - 3;11, David - 3;11, and Elena - 4;0) produced the diminutive forms of three nouns in the word list, namely pom - pomişor [promisor] 'tree > little.tree', ban - bănut 'coin - little.coin' and pat - pătut 'bed - beddy'. The diminutive suffix -uț (derived from the Latin -uceus, Iordan 1965: 311) will create a second syllable when attached to masculine or neuter target nouns, such that the final coda in the simple word will turn into the onset of the syllable containing the suffix: ban > bă.nuț 'coin', pat > pă.tuț 'cot/bed'. The other diminutive suffix, -şor, requires the epenthesis of the vowel $i$ to the root; this vocalic sound will constitute the nucleus of the second syllable of the derived word, whose onset will be the coda consonant of the simple form of the noun: pom + epenthetic $\mathrm{i}+-$ şor $>$ po.mi.şor [pomifor] 'little.tree'.

d) One other explanation for the lack of final coda deletion in Romanian could be related to the articulated forms of the nouns. In Romanian, nouns appear with either a definite or an indefinite article. The indefinite article is employed when introducing an entity in the discourse, after which reference to it will be made by means of a noun accompanied by the definite article or by a pronominal form. Four of the nine children who participated in the study produced the articulated forms of the nouns corresponding to the pictures in the elicitation task. Altogether, there were 12 cases of nouns accompanied by the definite article: focu(l) [fo.ku] 'the.fire' (Ciprian - 3;0 and Elena - 4;0), valu(l) [vı.lu] 'the.wave' (Ciprian - 3;0), trenu(l) [tre.nu] 'the.train'(Ioana - 3;3 and Mihai - 3;11), ceru(l) [fe.ru] 'the.sky' (Elena - 4;0), calu(l) [kı.lu] 'the.horse, renu(l) [re.nu] 'the.reindeer', and moşu(l) [mo.fu] 'the.old.man' (Ciprian - 3;0). In the case of one child (Elena - 4;0), I came across the plural form of val, i.e. valuri [vı.luri] 'waves'. Both the enclitic definite article and the plural suffix create an additional syllable, the final consonant of the targeted monosyllabic word turning again into the onset of the syllable containing the definite article of the plural suffix: val > va.lul 'the.wave'/ val > va.luri 'waves'.

Mara $(2 ; 1)$, without being asked by her mother what the picture in front of her eyes represented, uttered: Uau, lacu(I)'! 'Wow, the lake!' 
Table 4. Romanian children's articulated noun forms ${ }^{3}$

\begin{tabular}{|c|c|c|c|c|c|c|c|c|}
\hline $\begin{array}{l}\text { Target } \\
\text { word } \rightarrow \\
\text { Child } \downarrow\end{array}$ & $\begin{array}{l}\text { Val } \\
\text { 'wave' }\end{array}$ & $\begin{array}{l}\text { Foc } \\
\text { 'fire' }\end{array}$ & $\begin{array}{l}\text { Tren } \\
\text { 'train' }\end{array}$ & $\begin{array}{l}\text { Cal } \\
\text { 'horse' }\end{array}$ & $\begin{array}{l}\text { Moş } \\
\text { 'old man' }\end{array}$ & $\begin{array}{l}\text { Cer } \\
\text { 'sky' }\end{array}$ & $\begin{array}{l}\text { Ren } \\
\text { 'reindeer' }\end{array}$ & $\begin{array}{l}\text { Lac } \\
\text { 'lake' }\end{array}$ \\
\hline Mara 2;1 & & & & & & [t\}e.ru] & & [la.ku] \\
\hline Ciprian 3;0 & [va.lu] & [fo.ku] & & [ka.lu] & [mo.ju] & & [le.nu] & \\
\hline Elena 4;0 & [va.luri] & [fo.ku] & & & & [t\}e.ru] & & \\
\hline Ioana $3 ; 3$ & & & [te.nu $]^{1}$ & & & & & \\
\hline Mihai 3;11 & & & [te.re.nu] & & & & & \\
\hline
\end{tabular}

None of the children who employed the articulated nouns produced the final 'l' of the masculine/neuter article. An explanation for this could be the fact that the article is frequently dropped in adult speech, and the subjects may have imitated the adult input.

The parents of the children in the study were instructed that if the offspring did not produce the targeted word spontaneously, they should either provide them with a clue (Caretaker: Ce mănâncă câinele? 'What does the dog eat?' Un os 'A bone' = targeted word) or employ a forced-choice question (Caretaker: E cățelul slab sau gras? 'Is the dog slim of fat?' gras 'fat' = targeted word). When the child did not produce any response, the word was given a score of 0 and was not considered in the statistics. But there were also many situations in which the children did imitate, moreover correctly, the adult form. An important question that arises in connection with the elicitation by means of imitation is whether it yields similar results with the elicitation by means of pictures. Scholars seem to have different opinions concerning the two data collection procedures. Kay, Lesser, and Coltheart (1992) argued that the two methods of data collection would provide different results due to the fact that the imitation task involves more mental processing on behalf of the children to recognize the adult model. Other scholars found no differences between imitation and spontaneous picture naming (DuBois-Bernthal 1978), whereas still others (Johnson-Somers 1978) recommend that the imitation task should be avoided on the grounds that it does not provide an accurate picture of the child's phonological skills as the two scholars have discovered that in imitated production the subjects in their study produced consonants more accurately than in spontaneous speech. Thus, the large number of final coda consonants in my corpus could also be due to the fact that oftentimes my subjects imitated the adult model.

3 The onset clusters will not be discussed in this paper, though it is interesting to see that while Ioana $(3 ; 3)$ dropped the rhotic liquid in trenul 'the train' > ['te.nu], Mihai $(3 ; 11)$ broke the onset cluster by inserting an epenthetic vowel that copies the vowel in the root, i.e. /e/: [te.'re.nu], his pronunciation of the target word being a homophone of the noun terenul 'the land/ the ground'. 


\subsection{Coda simplification/repair strategies}

Though the children in the study produced the final coda, this was not always adultlike. Each of the two groups of consonants (obstruents and sonorants) underwent different simplification/repair strategies.

\section{A. Obstruents}

From among the obstruents, the plosives were the consonants that presented the highest number of allophones. Some of the children in the study aspirated the voiceless plosives, but not consistently so as to identify an individual pattern. Thus, the $/ \mathrm{p} /$ sound emerged under nine aspirated allophones in a total of 27 productions ( 3 words $\times 9$ children) - approximately $30 \%$; among the 27 cases of final $/ t /, 3$ aspirated forms were encountered, representing $11 \%$, while in the case of the final $/ \mathrm{k} /$ the aspirated allophones represented $5.5 \%$ of the total number of words (54) containing it. The aspiration of the voiceless plosives in coda position is considered by Goad and Brannen (2003) to bring further evidence in favour of the idea that children first treat final consonants more as onsets than codas due to the fact that the release properties of these consonants are more similar to onset than to coda position in the syllable.

Another process encountered in the production of plosives is devoicing, which affected the voiced consonants. Thus, the word cuib 'bird's nest' emerged as [kuip] five times, one of the productions being also accompanied by aspiration (Mara 2;1 $>$ [kuip $\left.{ }^{\mathrm{h}}\right]$ ). Devoicing plus aspiration was also encountered in the case of Ciprian's $(3 ; 3)$ production of the word steag 'flag' $>$ [steak $\left.{ }^{\mathrm{h}}\right]$.

In a number of cases, final voiceless consonants showed an even lower degree of sonority, the sounds having no audible release, as in Ciprian's pronunciation of the word lac [lık'] 'lake'. In other situations, the Romanian-speaking children produced the voiceless velar plosive / $\mathrm{k} /$ with a much higher degree of sonority, in the case of one subject (David - 3;11) this turning into an individual pattern.

In what concerns the fricative coda consonants, their production was clearer than that of the plosives. Of the 8 instances of the word mov 'mauve' ( 6 spontaneous and 2 imitated productions), only one showed devoicing (Ana $-3 ; 10$ [mof]). The dental fricatives /s/ and /z/ were fronted by two of the subjects, whose production of the words containing these sounds indicated a lisp (Ciprian - 3;0 and Mihai 3;11), which was confirmed by their mothers. Thus, they produced ceas 'watch', os 'bone', and gras 'fat' with an interdental, voiceless fricative [ $\theta]$. Another child in the study produced only two of the four words ending in /s/ with the same interdental fricative (David - 3;11), the other two having the correct final coda. In a similar vein, two children (Vlad - 3;10 and Mihai - 3;11) replaced the voiced alveolar fricative $/ z /$ with the voiced interdental fricative in the pronunciation of the adjective roz 
'pink': /roz/ > [roð]. The other fricative which was tested in coda position, i.e. / $/$, was affected by an opposite process, namely backing, the phonological process which involves the substitution of sounds produced in the front part of the oral cavity with the ones generated towards the back of the mouth. Three children in the study alternated between an anterior-palatal $/ \mathrm{S} /$ and a retroflex articulation: Ioana 3;3 and David 3;11 - duş 'shower' /duf/ > [dus] , Maya 3;5 - coş [kof] > [koș].

Fronting also affects the production of the coda affricate $/ \mathrm{ks} /$, rendered graphically as the letter $\mathrm{x}$ in pix 'ball pen'. The second element of the affricate turns into an interdental voiceless fricative both in the children with a lisp and in the production of another subject, Vlad 3;10 - /piks/ > [pik $\theta$ ]. The spontaneous production of the same word by Maya 3;5 was [pik], with the affricate [ks] being deaffricated to the voiceless stop [k]. After her mother provided her with the adult model, the girl uttered [pisk], her output being affected by metathesis, a process that makes two consonants within the same syllable switch place with each other.

\section{B. Sonorants}

From among the sonorants that appeared in coda position, $/ \mathrm{m} /$ and $/ \mathrm{n} /$ showed a $100 \%$ correct production both in spontaneous and in imitated production. As for the final coda liquids, the lateral liquid was pronounced correctly by all the children, while the rhotic one was twice substituted by 'l' (cer 'sky' $/ \mathrm{fer} />[\theta \mathrm{el}]$, Ciprian 3;0 and măr 'apple' /mər/ >[məl], Ana 3;10), whereas in other two situations it underwent backing, i.e. its alveolar place of articulation was replaced by a velar one: măr 'apple' /mər/ > [məy] ( $\mathrm{\gamma}=$ velar fricative).

\section{Conclusions}

The analysis of the data obtained by means of the picture-naming task showed that the Romanian-acquiring children in the study do not avail themselves of the final coda deletion (RQ-a), as is the case of most of their peers speaking various other languages (English or Spanish, for example). Strong support for the lack of this particular phonological process in the corpus is the type of input provided by adults in child-directed speech. On the one hand, caretakers use nouns with the definite article more often than with (or without) the indefinite article when they refer to various referents in the child's environment. Thus, when the definite article for the masculine and neuter gender $-l$ is attached at the end of a root with a $\mathrm{C}_{1-(2)} \mathrm{VC}_{1}$ structure, it triggers the epenthesis of the vowel sound $u$, which creates a second syllable whose onset is the coda singleton in the simple root: 
$\mathrm{C}_{1-(2)} \mathrm{VC}_{1}+u$ (epenthetic vowel) $+\mathrm{l}$ (definite masc. article) $>\mathrm{C}_{1-(2)} \mathrm{V} \mathrm{C}_{1} \mathrm{ul}$

The same phenomenon occurs when diminutive suffixes, very frequently employed in motherese, are attached to the nouns (RQ-d).

Nevertheless, we cannot state that Romanian-speaking children show mastery in producing final coda consonants as these are sometimes affected by other processes such as fronting, backing, or devoicing (RQ-b).

Thus, the results of the present study do not seem to support the common tendency of final consonant deletion reported for a large number of languages. In terms of final coda deletion, Romanian seems to pattern with Arabic (Owaida 2015), where the phonological process was identified to apply $5-15 \%$ of the time, the word-final consonants being produced correctly more often than those in initial or medial position (RQ-c).

\section{Limitations of the study and avenues for further research}

As mentioned previously, one possible reason for the lack of final consonant deletion in the corpus under investigation could be that the lowest age of my subjects $(2 ; 10)$ exceeds the age when English- and Hebrew-speaking children were reported to omit coda singletons (Adi-Bensaid 2015, Ingram 1974).

Another limitation of the study could be the fact that the word list I produced for the elicitation task was not tested in order to see the extent to which the youngest children were familiar with them. As the results showed, some of the children did not produce the expected response, not even after their caretakers had provided them with the adult model which the subjects were asked to imitate (altogether, there were 21 such cases out of a total of 342 expected productions). At the same time, the study was not genuinely cross-sectional as there were more children above the age of 3 than below this age. Consequently, in order to confirm or contradict the findings of the present study, it would be good to investigate a higher number of children, who should be equally distributed in age sub-groups that should contain, as much as possible, an equal number of girls and boys. Additionally, it would be advisable to pre-test the word list for the picture identification task and to select as stimuli only those items that children are familiar with in order to avoid including in the analysis the imitated productions as, according to Templin (1957), there might be a difference in the children's articulatory ability when the word is produced spontaneously and when it is repeated after the examiner or caretaker. Along the same line of reasoning, some scholars (Faircloth-Faircloth 1970, qtd. in Owaida 2015: 38-39) opine that "the correct production of a sound in a singleword elicitation task may not provide solid evidence in favour of a child's ability 
to also produce the sound in natural speech conditions". Others contradict this idea by stating that studies based on the production of single words in picturenaming tasks may provide more accurate information concerning the phonological acquisition. Thus, it would probably be useful to combine these two methods of speech elicitation.

Finally, for a higher reliability of transcription, a second specialist in phonetics should check whether the main investigator has misheard or mistranscribed certain pronunciations as children were recorded in various environments (in the park, in the churchyard, and mainly at home) where the background noise sometimes interfered with the child's production of the target words.

\section{References}

Adi-Bensaid, Limor. 2015. The role of prominence and position in the acquisition of codas in the speech of hearing-impaired children. In: Bat-El, Outi (ed.), The acquisition of Hebrew phonology and morphology. Leiden-Boston: Brill. 102117.

Avram, Andrei A. 2016. Issues on the acquisition of phonology by an EnglishRomanian bilingual child. Bucharest Working Papers in Linguistics XVIII/1. Bucharest: Editura Universității din Bucureşti.

Barlow, Jessica A. 2005. Phonological change and the representation of consonant clusters in Spanish: A case study. Clinical Linguistics and Phonetics (19): 659679.

Borràs-Comes, Joan-Prieto, Pilar. 2013. The acquisition of coda consonants by Catalan and Spanish speaking children: Effects of prominence and frequency of exposure. Probus 25(1): 1-24.

Bosma Smit, Ann. 1993. Phonological error distributions in the Iowa-Nebraska articulation norms project: Cconsonant singletons. Journal of Speech and Hearing Research (36): 533-547.

Buja, Elena. 2015a. Phonological development in Romanian monolingual children. In: Avram, L.-Sevcenco, A. (eds.), Bucharest Working Papers in Linguistics XVII/1. Bucharest: Editura Universității din Bucureşti. 23-42.

2015b. Syllable structure processes in child Romanian. East European and Balkan Studies 39(6): 1-29.

Daana, Hana A. 2017. Phonological development of an Arabic-English bilingual child during the one-word stage. Linguistics and Literature Studies 5(5): 354-364.

DuBois, A. Elaine-Bernthal, E. John. 1978. A comparison of three methods for obtaining articulatory responses. Journal of Speech and Hearing Disorders (43): 295-305. 
Fikkert, Paula. 1994. On the acquisition of prosodic structure. Leiden: Holland Institute of Generative Linguistics.

Freitas, Maria-Miguel, Matilde-Faria, Isabela. 2001. Interaction between prosody and morphosyntax: Plurals with codas in the acquisition of European Portuguese. In: Weisenborn, J.-Höhle, B. (eds.), Approaches to bootstrapping. Phonological, lexical, syntactic and neurophysiological aspects of early language acquisition. Vol. 2. Amsterdam-Philadelphia: John Benjamins. 45-58.

Gildersleeve, Christina-Davis Barbara-Stubbe Ellen. 1996. When monolingual rules don't apply: Speech development in a bilingual environment. Paper presented at the Annual Convention of the American Speech-Language-Hearing Association, Seattle, WA. MS.

Goldstein, Brian. 1995. Spanish phonological development. In: H. Kayser. (ed.), Bilingual speech-language pathology: An Hispanic focus. San Diego, CA: Singular. 17-38.

Goldstein, Brian-Citron, Patricia. 2001. An investigation of phonological skills in Puerto Rican Spanish speaking 2-year olds. Clinical Linguistics and Phonetics. (15): 343-361.

Goldstein, Brian-Washington S., Patricia. 2001. An initial investigation of phonological patterns in typically developing 4-year-old Spanish-English bilingual children. Language, Speech, and Hearing Service in Schools 32(3): 153-164.

Grunwell, Pamela. 1981. The development of phonology: A descriptive profile. First Language 3: 161-191.

Haelsig C., Patricia-Madison L., Charles. 1986. A study of phonological processes exhibited by 3-, 4-, and 5-year-old children. Language, Speech, and Hearing Service in Schools 17(2): 107-114.

Hua, Zhou. 2002. Phonological development in specific contexts. Studies of Chinesespeaking children. Clevedon: Multilingual Matters.

Ingram, David. 1974. Phonological rules in young children. Journal of Child Language (1): 49-64.

Iordan, Iorgu. 1956. Limba română contemporană [The Romanian contemporary language]. Bucharest: Editura Ministerului Învățămîntului.

Johnson, Sandra-Somers, Harold. 1978. Spontaneous and imitated responses in articulation testing. British Journal of Disorders of Communication (13): 107-116. Johnson, Wyn-Reimers, Paula. 2010. Patterns in child phonology. Edinburgh: Edinburgh University Press.

Kaur, Ramandeep-Manish, Anand-Subbarao, B. T. 2017. Phonological processes in Hindi speaking typically developing children across rural and urban areas. Language in India 17(1): 190-214. 
Kay, Janice-Lesser, Ruth-Coltheart, Max. 1992. Psycholinguistic assessment of language processing in aphasia (PLPA): An introduction. East Sussex, UK: Lawrence Earlbaum Associates Ltd.

Ladefoged, Peter. 2011. A course in phonetics ( $6^{\text {th }}$ edition). Boston, MA: Wadsworth Centage.

Lléo, Conxita. 2009. Prosodic licensing of codas in the acquisition of Spanish. Probus (15): 257-281.

Lléo, Conxita-Kuchenbrandt, Imme-Kehoe, Margaret-Trujillo, Cristina. 2003. Syllable final consonants in Spanish and German monolingual and bilingual acquisition. In: Muller, Natascha (ed.), (In)vulnerable domains in multilingualism. Amsterdam-Philadelphia: John Benjamins Publishing Company. 191-220.

Lust, Barbara. 2006. Child language acquisition and growth. Cambridge: Cambridge University Press.

Moskowitz I., Arlene. 1970. The two-year-old stage in the acquisition of English. Language 4(2), Part 1: 426-441.

Olmsted L., David. 1971. Out of the mouth of babes: Earliest stages in language learning. The Hague: Mouton de Gruyter.

Perumal, Radhakrishnan Chella-Vaidayanathan, Raghunathan-Prakash, Boominathan-Sreedevi, N. 2017. Phonological processes in typically developing Tamil speaking children. Language in India 17(7): 312-327.

Phoon, Hooi San-Abdullah-Anna Christina-Lay, Wah Lee-Puvaneswary, Murugaiah. 2014. Consonant acquisition in the Malay Language: A cross-sectional study of preschool aged Malay children. Clinical Linguistics and Phonetics 28(5): 329-345.

Prather, Elizabeth M.-Hedrick, Dona Lee-Kern, A. Carolyn. 1975. Articulation development in children aged two to four years. Journal of Speech and Hearing Disorders (40): 170-191.

Shaked, Galia. 1990. Early phonological development: Phonological processes in children 1;7 - 2;7 years old (in Hebrew). M.A. thesis. Department of Communication Disorders, Speech, Language and Hearing, Sackler Faculty of Medicine, Tel Aviv University. MS.

Smith, Neil. 1973. The acquisition of phonology. Cambridge: Cambridge University Press.

Stoel-Gammon, Carol-Dunn, Carla. 1985. Normal and disordered phonology in children. Austin, TX: Pro-Ed.

Stoicescu, Ioana. 2013. The acquisition of tense and aspect in Romanian. Bucharest: Editura Universității din Bucureşti.

Templin, C. Mildred. 1957. Certain language skills in children. Their development and interrelationships. Minneapolis, MN: University of Minnesota Press. 
Ulaimah Fifi, Wijayadi-Hamsia, Waode. 2016. Phonological acquisition in pronouncing Indonesian consonant words by two-year-old children. Tell Journal 4(2): 75-80.

Venkatesh, Lakshmi-Ramsankar, S.-Manjula, N. Nagaraja-Pushpa, Srinivasan P. 2010. Phonological processes in typically developing Tamil speaking children and Tamil-Telugu bilingual children. Journal of Indian Speech and Hearing Association 24(2): 121-133.

Vihman, Marilyn May. 1996. Phonological development: The origins of language in the child. Cambridge, Mass.: Blackwell.

Vihman, Marylin May-Ferguson, A. Charles-Elbert, Mary. 1986. Phonological development from babbling to speech: Common tendencies and individual differences. Applied Psycholinguistics (7): 3-40.

Zamuner, Tania-Gerken, Lou Ann. 1998. Young children's production of coda consonants in different prosodic environments. In: Clark, Eve (ed.), Proceedings of the $29^{\text {th }}$ Annual Child Language Research Forum. Centre for the Study of Language and Information, Stanford, CA. 13-25.

\section{Web sources}

Goad, Heather-Brannen, Kathleen. 2003. Phonetic evidence for phonological structure in syllabification. In: van de Weijer, J.-Heuven, V. J.-van der Hulst, H. (eds.), The phonological spectrum. Vol. 2: Suprasegmental structure. Amsterdam: John Benjamins. 3-30. https://epdf.pub/the-phonological-spectrumsuprasegmental-structure.html (downloaded on: 10.27.2019).

Jordão, Raquel-Frota, Sonia. 2010. The intonational phrase constraints coda development in EP. https://pdfs.semanticscholar.org/c6c7/571bdc498cb3c 11bdd24ed4965b8f660afc1.pdf?_ga=2.202499097.982442535.1571053175784457829.1563359491 (downloaded on: 09.20.2019).

Owaida, Husen. 2015. Speech sound acquisition and phonological error patterns in child speakers of Syrian Arabic: A normative study (unpublished doctoral thesis - City, University of London). http://openaccess.city.ac.uk/id/eprint/15182/1/ Owaida,\%20Husen\%20(redacted).pdf (downloaded on: 09.20.2019).

Perumal, Radhakrishnan Chella. 2019. Consonant acquisition and phonological processes in typically developing Tamil speaking children (unpublished $\mathrm{PhD}$ thesis - Sri Ramachandra University, College of Allied Health \& Sciences). https://shodhganga.inflibnet.ac.in/handle/10603/230294.

http://speech-therapy.ca/index.php/ro/free-stuff-ro-menu/carte-1 (downloaded on: 06.21.2019). 